\title{
Exposure-response relations of $\alpha$-amylase sensitisation in British bakeries and flour mills
}

\author{
Mark J Nieuwenhuijsen, Dick Heederik, Gert Doekes, Katherine M Venables, \\ Anthony J Newman Taylor
}

T H Huxley School of Environment, Earth Sciences and Engineering, Centre for Environmental Technology, Imperial College of Science, Technology and Medicine, London UK M J Nieuwenhuijsen

Department of Environmental Sciences, Environmental and Occupational Health Unit, Wageningen Agricultural University, PO Box 238, $6700 \mathrm{AE}$ Wageningen, The Netherlands

D Heederik

G Doekes

Department of Occupational and Environmental Medicine, Imperial College School of Medicine at the National Heart and Lung Institute, Manresa Road, London, UK $\mathrm{K} M$ Venables A J Newman Taylor

Correspondence to: Dr M J Nieuwenhuijsen, T H Huxley School of Environment, Earth Sciences and Engineering, Centre for Environmental Technology, Imperial CUof Science, Technology and Medicine, 48 Prince's Gardens, London SW7 2PE, UK. email m.nieuwenhuijsen@ic.ac.uk

Accepted 8 October 1998

\begin{abstract}
Objectives-To describe the levels of exposure to fungal $\alpha$-amylase in British bakeries and flour mills, and to describe the relation between exposure to $\alpha$-amylase and sensitisation to fungal $\alpha$-amylase.

Methods-495 personal flour dust samples were taken in seven British bakeries and flour mills and analysed for $\alpha$-amylase with an immunoassay. Workers at the sites were asked to fill out questionnaires on work related symptoms, smoking history, and work history, and they were skin prick tested with common allergens and fungal $\alpha$-amylase to assess sensitisation.

Results-Exposure to high concentrations of $\alpha$-amylase occur in a few areas of British bakeries and flour mills, and there can be considerable differences in exposures to $\alpha$-amylase between sites and between exposure groups, and even within similar exposure groups from different sites. Exposure to the highest concentrations of $\alpha$-amylase was found in the dispensing and mixing areas of the bakeries (geometric mean (GM) $39.7 \mathrm{ng} / \mathrm{m}^{3}$ ). Exposure to $\alpha$-amylase showed only a moderate correlation with concentrations of dust $(r=0.42)$ and flour aeroallergen $(r=0.46)$. The results also showed a relation between exposure to $\alpha$-amylase and sensitisation to fungal $\alpha$-amylase (prevalence ratio (PR) for medium exposure $3.9,95 \%$ confidence interval (95\% CI) 0.8 to 20.2 , PR for high exposure 9.9, 95\% CI 2.8 to 34.6 ) compared with the low exposure category). Atopic subjects had an increased risk of sensitisation, but this was not significant. Conclusion-This study suggests that exposure to $\alpha$-amylase is a considerable health risk in British bakeries and flour mills. A small proportion of workers are exposed to $\alpha$-amylase at concentrations that result in high rates of sensitisation. A reduction in exposure to $\alpha$-amylase is likely to reduce this risk.

(Occup Environ Med 1999;56:197-201)
\end{abstract}

Keywords: atopy; $\alpha$-amylase; bakers

The bakery industry has one of the highest rates of reported cases of occupational asthma in the United Kingdom. ${ }^{1} \alpha$-Amylase has been identified as one cause of occupational asthma in bakeries. ${ }^{23}$ A recent epidemiological study in British bakeries and flour mills found that 5\% of the workers had a positive skin prick test to $\alpha$-amylase, ${ }^{4}$ whereas an Italian study found a prevalence of $7.5 \% .^{5}$ A Swedish study in a factory producing semimanufactured products for restaurants and bakeries found that as many as $30 \%$ of the workers had a positive skin prick test to $\alpha$-amylase, but few $(n=2)$ measurements of exposure to $\alpha$-amylase were available. ${ }^{6} \mathrm{~A}$ Dutch study of bakers measured exposure to $\alpha$-amylase and found that there was an exposure-response relation between exposure to $\alpha$-amylase and rate of sensitisation to $\alpha$-amylase with rates varying from $1.4 \%$ in the low exposure group up to $30 \%$ in the high exposure group. ${ }^{7}$

Fungal $\alpha$-amylase is derived from Aspergillus oryzae and is a glycoprotein that catalyses the hydrolysis of internal $\alpha(1,4)$-glycosidic linkages in various polysaccharides. It is routinely added to the baking flour to hasten the baking process and improve bread quality. Amylase occurs naturally in flour (cereal amylase), but there seems to be only minimal immunological cross reactivity between fungal and cereal amylase. ${ }^{8}$ Airborne $\alpha$-amylase has been measured in Swedish, Finnish, and Dutch bakeries, but results are difficult to compare because different assays were used. However, considerable differences between various tasks, jobs, and areas were found within the different studies. ${ }^{9-11}$

In this paper we describe the results of analysis of $\alpha$-amylase that have now been performed on personal dust samples, which were collected in British bakeries and flour mills and which have been reported previously. ${ }^{12}$ A recently developed immunochemical method for analysis of $\alpha$-amylase was used. ${ }^{11}$ Secondly, we describe the exposureresponse relation of sensitisation to fungal $\alpha$-amylase.

\section{Methods and materials}

SITES, MEASUREMENTS OF EXPOSURE, AND EXPOSURE GROUPS

We surveyed three large modern bakeries, three flour mills, and one packing station. An occupational hygienist visited each site and divided the employees into exposure groups; 11 in each flour mill and packing station and 15 in each bakery. Exposure groups were anticipated to have different exposure levels based on the differences in tasks the workers did and departments where they worked. More details and a detailed description of the exposure groups have been reported elsewhere. ${ }^{12}{ }^{13}$

Briefly, a random sample of workers was invited to wear a personal sampler (Casella AFC 123, Casella London, Bedford) for a whole shift. The personal samplers were connected to seven hole sampling heads 
Table 1 Variation (\%) in a-amylase exposure levels explained by site and exposure group in British flour mills and bakeries

\begin{tabular}{lll}
\hline & \multicolumn{2}{l}{ Variation } \\
\cline { 2 - 3 } & Flour mills & Bakeries \\
\hline Site & 38 & 4 \\
Exposure groups & 24 & 29 \\
Sitexexposure groups & 11 & 13 \\
\hline
\end{tabular}

(Casella London, Bedford) containing polytetrafluoroethylene (PTFE) filters $(1.2 \mu \mathrm{m}$ pore size, $25 \mathrm{~mm}$ diameter; Sartorius Instruments, GB-Belmont, Surrey) and run at a flow rate of $2 \mathrm{l} / \mathrm{min} .{ }^{12} 13$

The samples were eluted with $0.5 \% \mathrm{v} / \mathrm{v}$ Tween $20(2 \mathrm{ml}$ in $0.1 \mathrm{M}$ ammonium hydrogen carbonate $\mathrm{pH}$ 7.65), freeze dried, and reconstituted before assay. The samples were analysed for fungal $\alpha$-amylase with a sandwich enzyme linked immunosorbent assay (ELISA), which used Fungamyl 1600S (Novo Nordisk) as the $\alpha$-amylase standard, and anti- $\alpha$-amylase antibodies raised in male New Zealand white rabbits through immunisation with Fungamyl 1600S (Novo Nordisk) as the antibody source. The method was developed and the analyses were carried out at the Department of Environmental Sciences at the Wageningen Agricultural University, the Netherlands. The method and its validation have been reported in detail elsewhere. ${ }^{11}$

The detection limit of the assay was 100 $\mathrm{pg} / \mathrm{ml}$. The airborne concentration was calculated as follows:

$\alpha$-amylase concentration in air $\left(\mathrm{pg} / \mathrm{m}^{3}\right)=$ (concentration in assay $(\mathrm{pg} / \mathrm{ml}) \times$ reconstituted volume $(0.9 \mathrm{ml})) /$ volume of air sampled $\left(\mathrm{m}^{3}\right)$.

For samples below the detection limit, two thirds of the detection limit $(100 \mathrm{pg} / \mathrm{ml})$ was used for statistical analyses. In total 478 samples were collected of which 229 (47.9\%) were below the detection limit. The data could be best described with a log normal distribution.

To study the exposure-response relation between exposure to $\alpha$-amylase and sensitisation to fungal $\alpha$-amylase (see later), we divided the population into three exposure categories: low (arithmetic mean (AM) $<5 \mathrm{ng} / \mathrm{m}^{3}$ ), medium $\left(5-15 \mathrm{ng} / \mathrm{m}^{3}\right)$, and high $\left(\geqslant 15 \mathrm{ng} / \mathrm{m}^{3}\right)$ similar to an earlier report by Houba et al. ${ }^{7}$ The division was made based on "exposure at time of study" and the "highest ever exposure" exposure group in which workers had worked. Twenty three workers could not be classified into these categories, because they worked in exposure groups where no measurements were taken and were excluded from exposure-response analyses.

POPULATION AND SENSITISATION

Workers at the seven sites, who had started work at the sites from 1 January 1986 onwards and worked for at least 1 month at the site, were invited to take part in a health study which took place in 1990. Details of the participants and study methods have been reported by Cullinan et al. ${ }^{4}$ Briefly, of the 401 eligible men and women, $344(86 \%)$ agreed to participate. Fifty six $(16 \%)$ workers reported exposure to flour before starting work at the sites and for a further $24(7 \%)$ this information was not available. All of them were excluded from the analyses. This left 264 employees for epidemiological analyses with an mean age of 28 years, and a mean duration of employment of 28 months; 181 (69\%) were men; 87 (34\%) were atopic; and 148 (57\%) smokers.

\section{QUESTIONNAIRES}

The participants were asked to fill out a symptom and smoking questionnaire. The following symptoms, if present since 1986, were recorded with dates of onset: chest tightness, wheeze, or difficulty in breathing (chest symptoms), itching of the eyes or nose, and itchy skin rash. Symptoms were considered to be work related if they were stated to improve over weekends or when on holidays for a week or more or if they were reported by the subject as being provoked by contact with flour. Symptoms reported to have started after first employment at the site were considered to be new.

Full smoking histories were obtained, but for the present analysis subjects were divided into those who had ever and those who had not smoked at least one cigarette a day for as long as a year, at least part of which had been during their employment at the sites.

SENSITISATION

To assess sensitisation, skin prick tests were carried out in a standard manner and considered positive if the mean wheal diameter was $\geqslant 3 \mathrm{~mm}$ greater than that of an inert control (1908 Bencard). Subjects were defined as atopic if they had one or more positive tests to three common allergens (B2 grass pollen 4100 Bencard, cat fur 3204 Bencard, and Dermatophagoides pteronyssinus 280 Bencard). Tests

Table 2 a-Amylase $\left(\mathrm{ng} / \mathrm{m}^{3}\right)$ in British flour mills and packing stations

\begin{tabular}{|c|c|c|c|c|c|c|c|c|c|c|c|c|c|c|c|c|c|}
\hline & \multirow[b]{2}{*}{$\%<d l$} & \multicolumn{4}{|c|}{ Site 1} & \multicolumn{4}{|c|}{ Site 5} & \multicolumn{4}{|c|}{ Site 6} & \multicolumn{4}{|c|}{ Site 10} \\
\hline & & $n$ & $A M$ & $G M$ & $G S D$ & $n$ & $A M$ & $G M$ & $G S D$ & $n$ & $A M$ & $G M$ & $G S D$ & $n$ & $A M$ & $G M$ & $G S D$ \\
\hline Wheat mill & 33 & 2 & 2.1 & 1.7 & 2.8 & & & & & 2 & 0.1 & 0.1 & 1.3 & 2 & 0.3 & 0.3 & 1.2 \\
\hline Flour mill & 37 & 6 & 3.6 & 1.9 & 4.0 & & & & & 6 & 0.1 & 0.1 & 1.4 & 7 & 14.1 & 5.4 & 7.7 \\
\hline Mixing area & 9 & & & & & 11 & 0.9 & 0.6 & 2.9 & & & & & & & & \\
\hline Packing area & 70 & 3 & 2.7 & 2.2 & 2.3 & 19 & 0.4 & 0.2 & 3.4 & 26 & 0.1 & 0.1 & 1.1 & 5 & 3.2 & 2.3 & 2.6 \\
\hline Warehouse & 50 & 4 & 0.3 & 0.2 & 1.7 & & & & & & & & & & & & \\
\hline Quality control & 25 & 4 & 0.7 & 0.6 & 1.8 & & & & & 2 & 0.2 & 0.2 & 1.3 & 2 & 0.7 & 0.7 & 1.5 \\
\hline Transport & 75 & 4 & 0.1 & 0.1 & 2.4 & & & & & & & & & & & & \\
\hline Hygiene & 0 & 4 & 7.3 & 4.6 & 3.2 & & & & & & & & & 14 & 9.2 & 4.9 & 3.2 \\
\hline Office & 100 & 2 & 0.1 & 0.1 & 1.1 & & & & & & & & & & & & \\
\hline Maintenance & 100 & & & & & & & & & 10 & 0.1 & 0.1 & 1.1 & & & & \\
\hline Miscellaneous & 33 & 4 & 1.8 & 1.3 & 2.4 & 2 & 0.1 & 0.1 & 1.0 & & & & & & & & \\
\hline
\end{tabular}

$\%<\mathrm{dl}=\%$ below the limit of detection; $\mathrm{n}=$ number of samples; $\mathrm{AM}=$ arithmetic mean; $\mathrm{GM}=$ geometric mean; GSD=geometric SD. 
Table 3 a-Amylase $\left(n g / m^{3}\right)$ in British bakeries

\begin{tabular}{|c|c|c|c|c|c|c|c|c|c|c|c|c|c|}
\hline \multirow[b]{2}{*}{ Bakeries: } & \multirow[b]{2}{*}{$\%<d l$} & \multicolumn{4}{|c|}{ Site 7} & \multicolumn{4}{|c|}{ Site 8} & \multicolumn{4}{|c|}{ Site 9} \\
\hline & & $n$ & $A M$ & $G M$ & $G S D$ & $n$ & $A M$ & $G M$ & $G S D$ & $n$ & $A M$ & $G M$ & $G S D$ \\
\hline Dispense or mixing & 9 & 3 & 47.3 & 39.7 & 2.2 & 6 & 22.7 & 1.4 & 16.8 & 13 & 24.9 & 6.0 & 6.0 \\
\hline Bread production & 20 & 23 & 1.5 & 0.4 & 5.4 & 11 & 2.5 & 1.3 & 3.5 & 10 & 61.4 & 5.8 & 17.9 \\
\hline Bread wrapping & 79 & 21 & 0.1 & 0.1 & 1.3 & & & & & 8 & 0.1 & 0.1 & 1.6 \\
\hline Roll production & 41 & 11 & 2.5 & 1.0 & 5.3 & 15 & 0.1 & 0.1 & 1.9 & 6 & 12.5 & 4.2 & 7.4 \\
\hline Roll wrapping & 67 & 12 & 0.6 & 0.2 & 3.6 & 5 & 0.1 & 0.1 & 1.4 & 7 & 0.1 & 0.1 & 1.2 \\
\hline Dough break & 67 & & & & & 8 & 0.2 & 0.1 & 2.6 & 1 & 5.2 & & \\
\hline Confectionary or flour & 39 & & & & & 15 & 0.3 & 0.2 & 8.4 & 8 & 1.0 & 0.3 & 4.0 \\
\hline Confectionary no flour & 73 & & & & & 12 & 0.1 & 0.1 & 1.7 & 21 & 1.2 & 0.1 & 4.0 \\
\hline Despatch & 85 & 9 & 0.2 & 0.1 & 1.8 & 6 & 0.1 & 0.1 & 1.4 & 19 & 0.1 & 0.1 & 1.4 \\
\hline Hygiene (inside) & 18 & 14 & 3.2 & 1.5 & 4.3 & 9 & 1.3 & 0.4 & 5.9 & 11 & 1.6 & 0.4 & 5.1 \\
\hline Hygiene (outside) & 43 & 13 & 2.1 & 0.5 & 6.9 & 13 & 0.7 & 0.2 & 3.7 & 2 & 0.8 & 0.7 & 2.3 \\
\hline Maintenance & 68 & 7 & 0.4 & 0.2 & 2.9 & 4 & 0.1 & 0.1 & 2.6 & 11 & 0.7 & 0.2 & 4.4 \\
\hline Quality control & 50 & & & & & & & & & 2 & 0.1 & 0.1 & 1.1 \\
\hline Miscellaneous & 0 & & & & & & & & & 5 & 1.5 & 0.9 & 3.3 \\
\hline
\end{tabular}

Footnotes as for table 2.

were also made with a prepared extract (10 $\mathrm{mg} / \mathrm{ml}$ ) of five Canadian and English wheat flours provided by the Flour Milling Bakers Research Association, with fungal $\alpha$-amylase (10 $\mathrm{mg} / \mathrm{ml}$, Novo Nordsk), and with mite Lepidoglyphus destructor (Allergon).

\section{STATISTICS}

The statistical software package SAS version 6.12 (SAS Institute, NC, USA) was used to carry out statistical analyses. Proc Means and Proc Univariate were used to carry out descriptive statistics. Analysis of variance (ANOVA) (Proc GLM and Proc Varcomp (SAS software)) was used to test differences in levels of exposure between sites and exposure groups, and to describe the variance components.

A modified Cox's proportional hazards models with Proc Phreg was used to calculate prevalence ratios for risk factors in the exposureresponse analyses. Differences of $\mathrm{p}<0.05$ (two sided) were considered significant.

\section{Results}

EXPOSURE LEVELS

Analysis of variance showed that there were significant differences in exposures to $\alpha$-amylase between sites $(\mathrm{p}<0.0001)$, exposure groups $(\mathrm{p}<0.0001)$, and the interaction of sites and exposure groups $(\mathrm{p}<0.0001)$ in the baker-

Table 4 Pearson correlation coefficients of log transformed dust, flour aeroallergen, and a-amylase concentrations

\begin{tabular}{lll}
\hline & $\begin{array}{l}\text { Flour aeroallergen } \\
\text { concentrations }\end{array}$ & $\begin{array}{l}\text { a-Amylase } \\
\text { concentrations }\end{array}$ \\
\hline $\begin{array}{l}\text { Dust concentration } \\
\text { Flour aeroallergen concentration }\end{array}$ & 0.65 & 0.42 \\
\hline
\end{tabular}

Table 5 Skin prick test results and symptoms by amylase exposure at the time of the study

\begin{tabular}{llll}
\hline & \multicolumn{3}{l}{$\begin{array}{l}\text { Amylase exposure categories at the time of the } \\
\text { study }\end{array}$} \\
\cline { 2 - 4 } & Low & Medium & High \\
\hline Subjects in each category (n) & 225 & 18 & 13 \\
a-Amylase exposure (mean (SD) ng/m $\left.{ }^{3}\right)$ & $0.7(0.8)$ & $10.7(2.2)$ & $46.7(16.6)$ \\
Atopic (n (\%)) & $73(32.4)$ & $7(38.9)$ & $7(53.9)$ \\
Smoker (n (\%)) & $125(53.9)$ & $14(73.7)$ & $9(69.2)$ \\
Positive skin prick test to (n (\%)): & $7(3.1)$ & $3(16.7)$ & $2(15.4)$ \\
$\quad$ Fungal amylase & $7(3.1)$ & $2(11.1)$ & $1(7.7)$ \\
$\quad$ Mixed flour & $14(6.0)$ & $0(0)$ & $2(15.4)$ \\
New work related symptoms (n (\%)): & $38(16.4)$ & $4(21.0)$ & $3(23.1)$ \\
$\quad$ Chest & $12(5.2)$ & $1(5.3)$ & $4(30.8)$ \\
$\quad$ Eyes and nose & & & \\
$\quad$ Skin & & & \\
\hline
\end{tabular}

ies. In the flour mills and packing station there were significant differences between sites $(p<0.0001)$ and exposure groups $(p<0.0001)$, but no significant interaction between sites and exposure groups $(p<0.08)$. In the flour mills and packing stations the sites explained the largest proportion of the variation in exposures to $\alpha$-amylase $(38 \%)$, whereas in the bakeries the exposure groups were the largest source of variation $(29 \%$, table 1$)$. The exposures to $\alpha$-amylase are therefore shown by site and exposure group.

In the flour mills and packing stations the highest exposures to $\alpha$-amylase were measured for workers in the flour mill and packing station, and cleaners (hygiene) of site 10, followed by workers in the flour mill, and packing station, and cleaners of site 1 (table 2). Exposures to $\alpha$-amylase in other exposure groups and flour milling and packing sites were considerably lower. At site 6 none of the samples had detectable $\alpha$-amylase. In the bakeries high activities of $\alpha$-amylase were measured in the dispensing and mixing areas, but there were differences in exposures between the sites in these areas (table 3). Relatively high concentrations activities of $\alpha$-amylase were also measured at the bread and roll production areas of site 9 , but at the same areas in the other bakeries were considerably lower. Workers in other areas were generally exposed to much lower concentrations although there were some exceptions such as the cleaners (hygiene).

The correlation between log transformed $\alpha$-amylase and $\log$ transformed dust or flour aeroallergen concentrations, which have been reported elsewhere, ${ }^{12}$ were weak to moderate (table 4). When the exposures were not transformed the Pearson correlation coefficients were even lower-for example, 0.13 for dust and $\alpha$-amylase.

\section{EXPOSURE-RESPONSE RELATION}

In total $12(5 \%)$ workers had a positive skin prick test to fungal $\alpha$-amylase, of whom none had new work related chest symptoms, one $(8 \%)$ had new work related eyes and nose symptoms, and one $(8 \%)$ had new work related skin symptoms.

The number of workers in the medium and high exposure categories was small due to the 
Table 6 Skin prick test results and symptoms by highest ever level of amylase exposure

\begin{tabular}{|c|c|c|c|}
\hline & \multicolumn{3}{|c|}{ Highest ever amylase exposure categories } \\
\hline & Low & Medium & High \\
\hline Subjects in each category $(\mathrm{n})$ & 203 & 21 & 17 \\
\hline Mean (SD) $\alpha$-amylase exposure $\left(\mathrm{ng} / \mathrm{m}^{3}\right)$ & $0.8(0.8)$ & $10.5(2.3)$ & $48.0(16.6)$ \\
\hline Atopic $(\mathrm{n}(\%))$ & $70(34.5)$ & $7(33.3)$ & $9(52.9)$ \\
\hline Smoker $(\mathrm{n}(\%))$ & $112(53.3)$ & $15(68.2)$ & $12(70.6)$ \\
\hline \multicolumn{4}{|l|}{ Positive skin prick test to $(\mathrm{n}(\%))$ : } \\
\hline Fungal amylase & $5(2.5)$ & $2(9.5)$ & $5(29.4)$ \\
\hline Atopics & $3(4.3)$ & $2(28.6)$ & $3(33.3)$ \\
\hline Non atopics & $2(1.5)$ & $0(0)$ & $2(25.0)$ \\
\hline Non-smokers & $3(3.3)$ & $1(14.3)$ & $2(40.0)$ \\
\hline Smokers & $2(2.5)$ & $2(15.4)$ & $1(11.1)$ \\
\hline Mixed flour & $7(3.5)$ & $2(9.5)$ & $1(5.9)$ \\
\hline \multicolumn{4}{|l|}{ New work related symptoms (n (\%)): } \\
\hline Chest & $13(6.2)$ & $1(4.6)$ & $2(11.8)$ \\
\hline Eyes and nose & $34(16.2)$ & $5(22.7)$ & $3(17.7)$ \\
\hline Skin & $12(5.7)$ & $1(4.6)$ & $4(23.5)$ \\
\hline
\end{tabular}

Table 7 Prevalence ratios of sensitisation to a-amylase relative to atopy and a-amylase highest exposed ever exposure categories in British bakeries and flour mills

\begin{tabular}{llll}
\hline Risk factor & $\begin{array}{l}\text { Prevalence } \\
\text { ratio }\end{array}$ & $95 \%$ CI & p Value \\
\hline $\begin{array}{l}\text { Atopy } \\
\text { Exposure category: }\end{array}$ & 2.9 & 0.8 to 9.7 & 0.09 \\
$\quad$ Low & 1.0 & & \\
$\quad$ Medium & 3.9 & 0.8 to 20.2 & 0.10 \\
High & 9.9 & 2.8 to 34.6 & 0.003 \\
\hline
\end{tabular}

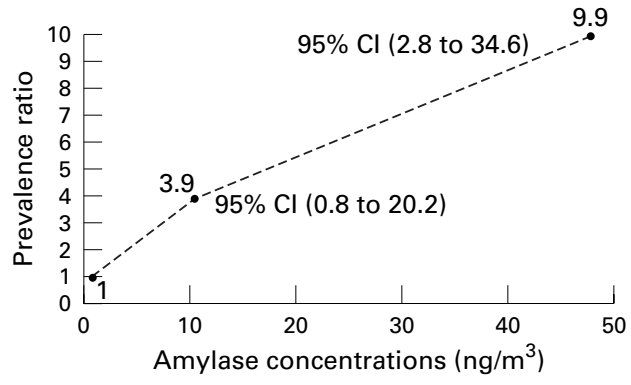

Prevalence ratios of sensitisation to a-amylase plotted against a-amylase highest ever exposures to a-amylase $\left(\mathrm{ng} / \mathrm{m}^{3}\right)$ in bakeries and flour mills in the United Kingdom.

low exposures at the sites (tables 5 and 6 ). A few workers could not be included in the analyses because information on exposure to amylase was missing. There was an increase in the percentages of smokers and atopic subjects with increasing exposure. Atopic subjects were significantly less likely to smoke than nonatopic subjects $(46 \% v 62 \%, \mathrm{p}<0.05)$. There was an increase in the percentage of workers with new work related symptoms and sensitisation with increasing exposure. The increase in new work related symptoms was clearest with the categorisation that used "exposure at time of study". The increase in sensitisation to fungal $\alpha$-amylase was steepest with the categorisation that used "highest exposure ever".

Regression analyses showed a significant independent exposure-response relation between exposure to $\alpha$-amylase, categorised by "highest exposure ever" and sensitisation to fungal $\alpha$-amylase (table 7 ; figure). Atopic subjects had an increased risk of sensitisation, but this was not significant in the model. Smokers showed a slightly decreased risk of sensitisation ( $\mathrm{PR}=0.7,95 \% \mathrm{CI} 0.2$ to 2.1 ), but this was not significant and was left out of the final model.

\section{Discussion}

In this paper we have shown that high exposures to $\alpha$-amylase occur in certain areas of British bakeries and flour mills, and that there can be considerable differences in exposures to $\alpha$-amylase between sites and between exposure groups, and between the same exposure group from different sites. The highest $\alpha$-amylase exposures were found in the dispensing and mixing areas of the bakeries. Exposure to $\alpha$-amylase showed only a moderate correlation with concentrations of dust and flour aeroallergen. We have also shown an exposure-response relation between exposure to $\alpha$-amylase and sensitisation to fungal $\alpha$-amylase. Atopic subjects had an increased risk of sensitisation, but this was not significant.

Few studies have measured $\alpha$-amylase exposures in bakeries and flour mills. ${ }^{6-11}$ The techniques to measure $\alpha$-amylase exposures have only been recently developed. $\alpha$-Amylase exposures from one study by Houba et $a l^{11}$ are directly comparable to the $\alpha$-amylase exposures in this paper, because the same method was used, although there might be some slight differences because of different extraction methods and different methods and durations of storing the samples. These differences, however, would be expected to be small compared with differences found between different exposure groups and sites. In the other studies ${ }^{69} 10$ the enzyme activity of $\alpha$-amylase was measured in airborne dust samples. For the exposure assessment of fungal $\alpha$-amylase allergens these methods have two important limitations. ${ }^{11}$ First of all, inactive or denatured enzymes were not measured, but could possibly still act as allergens, which could lead to underestimation of the exposures. Sander and Baur ${ }^{14}$ showed that digested fragments of $\alpha$-amylase were still able to bind to IgE antibodies. Secondly, these methods measure the amylase activity of both fungal and cereal origin. Amylase occurs naturally in flour, but there is minimal immunological cross reactivity between cereal and fungal amylase. ${ }^{8}$ Immunochemical techniques which measure the amylase related to adverse health effects may therefore be preferred.

Houba et $a l^{11}$ found the highest $\alpha$-amylase exposures among dough makers producing crispbakes, a kind of breakfast toast (GM 18.1 $\mathrm{ng} / \mathrm{m}^{3}$ ), followed by the dough makers in wheat bread production sites (GM $0.8 \mathrm{ng} / \mathrm{m}^{3}$ ), and bread and mixed bakers in small traditional bakeries $\left(0.2-0.3 \mathrm{ng} / \mathrm{m}^{3}\right)$. There are no crispbake production areas in the United Kingdom as far as we are aware, but we found exposures similar to the crispbake areas in the Dutch study. As in the Dutch study, higher exposures to $\alpha$-amylase were found in mixing and dispensing areas of bakeries, although there was a considerable difference in exposures in these areas between sites. An important finding was the considerable differences in $\alpha$-amylase exposures between the same exposure groups from different sites, even though similar work was done. This might be due to the amount of fungal $\alpha$-amylase that was added to the flour, as total dust concentrations were generally 
similar. ${ }^{12}$ Unfortunately no information had been collected on the amount of fungal $\alpha$-amylase added to the flour. One flour mill (site 10) and one bakery (site 9) had considerable $\alpha$-amylase exposure in several areas, whereas at other sites this was restricted to a few areas or none at all (site 5).

Overall there was a low to moderate correlation between $\alpha$-amylase exposures concentrations and concentrations of dust or flour aeroallergen. It seems that exposure to concentrations of dust are not a good indicator for $\alpha$-amylase exposures, and that these should be measured to assess $\alpha$-amylase activities.

We found a prevalence of $5 \%$ for sensitisation to fungal $\alpha$-amylase, with a clear increase with increasing exposure to amylase. Recent epidemiological studies have found prevalences varying from $5 \%-30 \%$ for positive skin prick test responses to $\alpha$-amylase in populations in the baking industry. ${ }^{4-7}$ Crude prevalences of sensitisation to $\alpha$-amylase in baking populations are difficult to interpret as there is no information on baseline rates of sensitisation of $\alpha$-amylase in the general population. However, if an exposure-response relation can be shown then they become more meaningful and can be used to set a standard to prevent sensitisation.

Houba et al found that 9\% of bakery workers had a positive skin prick test to $\alpha$-amylase, and that there was a direct relation between the exposure to $\alpha$-amylase and a positive skin prick test to $\alpha$-amylase. Overall, they found prevalences of $1.4 \%, 12.8 \%$, and $30.4 \%$ for the low (GM $0.7 \mathrm{ng} / \mathrm{m}^{3}$ ), medium (GM $1.3 \mathrm{ng} / \mathrm{m}^{3}$ ), and high $\left(18.1 \mathrm{ng} / \mathrm{m}^{3}\right)$ exposure groups respectively (prevalence rate ratios of 8.6 (95\% CI 1.01 to 74 ) and 15.9 (95\% CI 1.95 to 129 ) respectively for the medium and high exposure group compared with the low exposure group). This relation was clearer among atopic subjects than non-atopic subjects. Atopic subjects in the highest exposure group had a prevalence of $>50 \%$.

We found a direct relation between exposure to $\alpha$-amylase and sensitisation to fungal $\alpha$-amylase. The relation was clearest with the categorisation "highest ever exposure", which might be expected if workers moved away from high exposure areas after becoming sensitised, or after the development of symptoms. Those who moved away still showed a decrease over time in specific IgE. Symptoms might be anticipated to show a closer relation with exposure "at time of study" as avoidance of exposure could allow symptoms to improve. In this study we focused on sensitisation rather than symptoms because it is a more specific outcome. Exposure-response relations between exposure to flour dust and flour aeroallergen and outcomes such as symptoms and sensitisation to flour have been described in this population. ${ }^{4}$ Few people with sensitisation had new work related symptoms, which might in part be explained by the cross sectional design of the study; those with symptoms may have moved to low exposure areas, or have left the sites altogether after the onset of symptoms. This study showed also an increased risk of atopic subjects, but this was not significant. An attempt was made to describe separate exposure-response relations for atopic and non-atopic subjects, but this resulted in few workers in some categories and unstable estimates, which are therefore not shown.

This study suggests that exposure to $\alpha$-amylase is a significant health risk for those employed in bakeries and flour mills. A small proportion of workers are exposed to concentrations of $\alpha$-amylase that cause a high rate of sensitisation. A reduction in $\alpha$-amylase exposures is likely to reduce this risk. We acknowledge the help of Mr L van Amelsvoort with the
environmental sampling, Miss J Welch with air filter elution, $\mathrm{Mr}$ environmental sampling, Miss J Welch with air filter elution, Mr J Spithoven for amylase analyses, Mr F Gill and Mrs D Glass for
advice on exposure assessment, our coworkers Dr CP advice on exposure assessment, our coworkers Dr CP
Sandiford, Dr S Gordon, Mr D Lowson, Dr RD Tee, Dr P Cullinan, and Professor JC McDonald, and the management Cullinan, and Professor JC McDonald, and the management
and workers at the different sites for their cooperation. The work was funded by the Health and Safety Executive, the National Asthma Campaign, The Royal Society, the Department of Health and Social Security, the Clinical Research Committee of the Royal Brompton Hospital and a Concerted Action grant from the European Community (contract no BMH1-CT941446).

1 Meredith SK, Taylor VM, McDonald JC. Occupational respiratory disease in the United Kingdom 1989: a report to the British Thoracic Society and the Society of Occupational Medicine by the SWORD project group. $\mathrm{Br} F$ Ind Med 1991;48:292-8.

2 Flindt, MLH. Allergy to $\alpha$-amylase and papain. Lancet 1979;i:1407-8.

3 Baur X, Fruhmann G, Haug B, et al. Role of aspergillus amylase in Baker's asthma. Lancet 1986;i:43.

4 Cullinan P, Lowson D, Nieuwenhuijsen MJ, et al. Work related symptoms, sensitisation, and estimated exposure in workers not previously exposed to flour. Occup Environ Med 1994;51:579-83.

5 de Zotti R, Larese F, Bovendi M, et al. Allergic airway disease in Italian bakers. Occup Environ Med 1994;52:27983.

6 Brisman J, Belin L. Clinical and immunological responses to occupational exposure to $\alpha$-amylase in the baking industry. Br f Ind Med 1991;48:604-8.

7 Houba R, Heederik D, Doekes G, et al. Exposuresensitization relationship for $\alpha$-amylase allergens in the baking industry. Am F Respir Crit Care Med 1996;154:1306.

8 Sandiford CP, Tee RD, Newman Taylor AJ. The role of cereal and fungal amylase in cereal hypersensitivity. Clin Exp Allergy 1994;24:549-57.

9 Burdorf A, Lillienberg L, Brisman J. Characterization of exposure to inhalable flour dust in Swedish bakeries. Ann Occup Hyg 1994;38:67-78.

10 Jauhiainen A, Louhelainen K, Linnainmaa M. Exposure to dust and $\alpha$-amylase in bakeries. Appl Occup Environ Hyg 1993;8:721-5.

11 Houba R, van Run P, Doekes G, et al. Airborne levels of $\alpha$-amylase allergens in bakeries. $\mathcal{F}$ Allergy Clin Immunol 1997;99:286-92

12 Nieuwenhuijsen MJ, Sandiford CP, Lowson D, et al. Dust and flour aeroallergen exposure in flour mills and bakeries. Occup Environ Med 1994;51:584-8.

13 Nieuwenhuijsen MJ. Exposure to aeroallergens: determinants, exposure levels, and skin prick test reactions in bakeries, flour mills and research institutes [PhD thesis]. London: University of London, 1993.

14 Sander I, Baur X. Evidence for continuous B-cell epitopes on $\alpha$-amylase of Aspergillus oryzae (Asp o II). F Allergy Clin Immunol 1994;93:265. 